\title{
SÍMBOLO Y MITO EN EL MOVIMIENTO SIMBOLISTA FRANCÉS: HENRI DE RÉGNIER
}

\author{
Nuria Cabello Andrés \\ Universidad de La Rioja
}

\section{RESUMEN}

El presente trabajo aborda la importancia del símbolo en el movimiento simbolista francés. El símbolo es el elemento sobre el que se asienta la estética del simbolista. Los poetas simbolistas se servirán asimismo del mito considerado en cuanto símbolo para plasmar sus grandes preocupaciones e ilustrar su pensamiento idealista. Para mostrar la relación fundamental que une ambos elementos, nos centraremos en cuatro de los mitos más relevantes de la fin de siècle: Narciso, Psique, Orfeo y Pigmalión mediante ejemplos extraídos de la obra de Henri de Régnier. Estos mitos revelan una de las grandes inquietudes del periodo finisecular: la dicotomía yo/otro.

Palabras clave: símbolo, mito, movimiento simbolista, fin de siècle, Henri de Régnier.

\section{SYMBOL AND MYTH IN THE FRENCH SYMBOLIST MOVEMENT:}

HENRI DE RÉGNIER

\section{Abstract}

The present work addresses the importance of symbol in the French symbolist movement. Symbol is the element on where the symbolic aesthetics is based. The symbolist poets will also use the myth, which is considerated like a symbol to embody their intense worries and to illustrate this idealistic thinking. To show the fundamental relation, which joins both elements, we will focus on four of the most important myths of the fin-de-siècle: Narcissus, Psyque, Orpheus and Pygmalion by means of examples torn from Henri de Régnier's work. These myths reveal one of the great interests of the fin-de-siècle period: the self/other dichotomy.

KeYwords: Symbol, myth, symbolist movement, fin de siècle, Henri de Régnier. 


\section{INTRODUCCIÓN}

El Simbolismo es un movimiento heteróclito en el que se concitan numerosas tendencias y que recibe influencias variadas (vid. Brunel 1974). Sin embargo, como toda nueva tendencia, el Simbolismo reivindica su carácter novedoso y por ello parece renegar de sus orígenes, en especial del movimiento romántico. De esta manera, el movimiento simbolista se postula como una nueva manera de concebir la poesía.

Jean Moréas en el Manifiesto Simbolista publicado el 18 de septiembre de 1886 en Le Figaro sienta las bases de la nueva escuela. Dichas ideas son asimismo el punto de partida de Maurice Maeterlinck para explicitar las concepciones de esta nueva literatura:

La haute poésie, à la regarder de près, se compose de trois éléments principaux: D’abord la beauté verbale, ensuite la contemplation et la peinture passionnée de ce qui existe réellement autour de nous et en nous-mêmes, c'est-à-dire la nature et nos sentiments, et enfin, enveloppant l'œuvre entière et créant son atmosphère propre, l'idée que le poète se fait de l'inconnu dans lequel flottent les êtres et les choses qu'il évoque, du mystère qui les domine et les juge et qui préside à leurs destinées. Il ne me paraît pas douteux que ce dernier élément est le plus important. Voyez un beau poème, si bref, si rapide qu'il soit. Rarement, sa beauté, sa grandeur se limitent aux choses connues de notre monde. Neuf fois sur dix il les doit à une allusion aux mystères des destinées humaines, à quelque lien nouveau du visible à l'invisible, du temporel à l'éternel (Maeterlinck 1979: X-XI).

Maeterlinck enuncia en este fragmento los tres elementos esenciales de la gran poesía. El predominio de uno u otro de esos rasgos define las diferentes tendencias literarias de la literatura francesa del siglo xix: por una parte, el Romanticismo, centrado en la pintura de la naturaleza y de los sentimientos humanos; por otra, el Parnaso, que prima el culto a la belleza de la forma, obviando la pintura de la realidad y, por supuesto, el misterio en la poesía. La nueva tendencia tiene su eje en el último elemento; así, la poesía para los jóvenes escritores se debe a la búsqueda del ideal, de lo eterno, de lo que nos une a lo desconocido, partiendo para ello de la realidad, a través del logos. La manera de lograr este objetivo será mediante la unión de sentidos y sonidos en principio extraños y desconocidos, que generan el símbolo, el elemento que nos permite superar lo banal y lo cotidiano para acceder a lo inmaterial y lo superior. La escritura simbolista, por lo tanto, conjuga los tres elementos expuestos por Maeterlinck para crear algo nuevo. Eso es lo que la distingue de los movimientos coetáneos y por ello, es la auténtica poesía ${ }^{1}$.

${ }^{1}$ Creemos que este concepto de poesía hay que entenderlo en un sentido amplio, es decir, que hace referencia a la literatura en general, y ese es el sentido en que vamos a emplearlo en las páginas siguientes. Así, estas concepciones sobre el símbolo y sobre la poesía pueden aplicarse a toda obra literaria de este movimiento. 
En este sentido, el objetivo fundamental de este artículo consistirá en examinar el concepto de símbolo en el movimiento simbolista y la relación de este con el mito, que para los autores simbolistas no es sino una figuración del símbolo. Después de precisar la idea de mito en el Simbolismo, analizaremos la significación de algunos de los mitos esenciales del periodo fin de siglo: Narciso, Psique, Orfeo y Pigmalión. Para llevar a cabo esta tarea, ilustraremos nuestro trabajo con ejemplos de textos narrativos de algunos autores representativos del movimiento, en especial de Henri de Régnier.

\section{EL CONCEPTO DE SÍMBOLO}

El Simbolismo coloca en primer término la utilización del símbolo como único y verdadero medio y fin de la poesía. Las palabras mundanas no pueden trasmitir la verdad. Como dice Mallarmé:

Nommer un objet, c'est supprimer les trois quarts de la jouissance du poème qui est faite du deviner peu à peu; le suggérer, voilà le rêve. C'est le parfait usage de ce mystère qui constitue le symbole: évoquer petit à petit un objet pour montrer un état d'âme, ou, inversement, choisir un objet et en dégager un état d'âme, par une série de déchiffrements (Huret 1891: 60).

No obstante, atribuirse la paternidad única del símbolo no parece algo muy honesto por parte del movimiento simbolista ${ }^{2}$. La concepción del símbolo en el Simbolismo no puede entenderse sin la contribución esencial de los románticos ${ }^{3}$, que instituyeron esta figura como forma de expresión privilegiada en el arte que permite «'expression de l'indicible» (Illouz 2004: 153). Para los románticos alemanes solo podremos conocer la auténtica realidad a través del símbolo, que elimina lo que nos separa del mundo intelectual, de la idea. Es la famosa Teoría de las Correspondencias.

En efecto, la teoría del símbolo en el Simbolismo tiene una de sus bases en la Teoría de las Correspondencias de Baudelaire ${ }^{4}$, quien deja claro en su famoso soneto Correspondances que «... le poète doit [...] savoir ces mystérieuses correspondances et les faire connaître» (Léoutre et Salomon 1970: 11). Siguiendo esta idea, el símbolo para los simbolistas sería una forma primordial de Correspondencia por-

${ }^{2}$ Y así lo reconoce Henri de Régnier en su entrevista con Jules Huret: «Oui, je le sais, nous n'inventons pas le symbole, mais jusqu' ici le symbole ne surgissait qu' instinctivement dans les œuvres d'art, en dehors de tout parti pris, parce qu'on sentait qu'en effet il ne peut pas y avoir d'art véritable sans symbole. Le mouvement actuel est différent: on fait du symbole la condition essentielle de l'art. On veut en bannir délibérément, en toute conscience, ce qu'on appelle, -je crois,- les contingences, c'est-à-dire les accidents de milieu, d'époque, les faits particuliers» (Huret 1891: 93).

3 Para una mejor comprensión de la estética romántica y por ende de su concepción del símbolo, remitimos a la obra de Javier Hernández-Pacheco (1995).

${ }^{4}$ Baudelaire recoge a su vez esta teoría de Hoffmann y refleja las concepciones de la Analogía Universal de los Iluministas, Martinistas y de Swedenborg. 
que «[il] permet de deviner les liens invisibles entre le monde sensible et le monde inteligible» (Juszezak 1985: 23).

Así, la escritura simbolista se configura como una síntesis, una relación novedosa con el mundo, cimentada en el uso del símbolo:

La poésie symboliste est travail sur une vision qui est celle de la vie dans toute sa complexité, et avec ses mystères que la raison ne peut élucider. Cette vision est conçue dans sa relation à l'individu et à son niveau cosmique, en toute conscience du caractère subjectif d'une telle aproche. Conscient des limites de sa tentative, le poète n'ambitionne guère une traduction claire de ce qui reste insondable, mais une évocation [...]. Dès lors, l'expression symbolique s'impose. Observée sous des angles différents, une même figure paraît une autre. Le symbole n'en fixe pas une face, mais les présente toutes (Elgart 2014: 91).

A pesar de la coherencia de estos fundamentos, la puesta en práctica del símbolo por parte de los autores de la época no revela tanta coherencia. El principal escollo viene dado por la confusión entre símbolo y alegoría (vid. Backès 1980) ${ }^{5}$. Los escritores que no dudan en separar ambos conceptos proclaman la supremacía del símbolo; así, por ejemplo, Maeterlinck:

[...] je crois qu'il y a deux sortes de symboles: l'un qu'on pourrait appeler le symbole a priori; le symbole, de propos délibéré; il part d'abstraction et tâche de revêtir d'humanité ces abstractions. Le prototype de cette symbolique, qui touche de bien près à l'allégorie, se trouverait dans le second Faust et dans certains contes de Goethe, son fameux Mährchen aller Mährchen, par exemple. L'autre espèce de symbole serait plutôt inconscient, aurait lieu à l'insu du poète, souvent malgré lui, et irait, presque toujours, bien au-delà de sa pensée: c'est le symbole qui naît de toute création géniale d'humanité; le prototype de cette symbolique se trouverait dans Eschyle, Shakespeare, etc. (Huret 1891: 124-125).

Pese a que Maeterlinck habla de dos tipos de símbolo y no se refiere al concepto de alegoría explícitamente, podemos afirmar con el autor que el primer tipo de símbolo que menciona, le symbole à priori, corresponde a la alegoría, y el segundo, al símbolo, tal y como se concibe en el Simbolismo.

En la misma línea se sitúa Henri de Régnier, quien contrapone ambos conceptos, dejando claro que el símbolo es superior a la alegoría y que lo que distingue claramente a los jóvenes poetas del momento es precisamente la utilización del símbolo:

5 Illouz advierte de que la confusión ente los dos conceptos, separados nítidamente en el Romanticismo, está motivada en parte por Charles Baudelaire: «Alors que le Romantisme avait institué l'opposition du symbole et de l'allégorie au détriment de l'allégorie, la réévaluation baudelairienne de celle-ci, promue en figure majeure de la modernité littéraire, implique une toute autre pensée du signe. À la différence du symbole, l’allégorie ne suppose plus cette confiance dans le langage qu'autorisait l'ancrage du symbole dans une ontologie; dans l'allégorie, le signe, sans relève métaphysique, n’a plus d'autre signification qu'historique...” (2004: 159). 
Le Symbole est le couronnement d'une série d'opérations intellectuelles qui commencent au mot même, passent par l'image et la métaphore, comprennent l'emblème et l'allégorie. Il est la plus parfaite, et la plus complète figuration de l'Idée. C'est cette figuration expressive de l'Idée par le Symbole que les Poètes d'aujourd'hui tentèrent et réussirent plus d'une fois (Régnier 1901b: 333-334).

Aunque la propuesta teórica de Henri de Régnier, que se repite en otros escritos, es muy precisa, este autor acaba cayendo, en no pocas ocasiones, en la alegoría cuando parece estar haciendo uso del símbolo. Ejemplos reveladores de este hecho son "L'Homme et la Sirène» (Aréthuse, 1895), auténtica alegoría del poeta y de su relación con la naturaleza, y "Le sang de Marsyas» (La cité des eaux, 1902), figura tras la que se adivina Mallarmé.

La concepción del símbolo por parte de los autores fin de siglo, a pesar de las inconsistencias, nos permite entender la importancia que adquiere en la literatura simbolista la utilización del mito ${ }^{6}$, el cual «n'est pas seulement un trait fabuleux concernant des divinités ou des personnages qui ne sont que des divinités défigurées, c'est avant tout un récit à double sens»(Mazel 1968: 333) ${ }^{7}$.

El carácter universal y atemporal del mito lo une al símbolo, ambos comparten rasgos y, además, permiten conocer no la imagen exterior sino la idea, no lo fugaz sino lo duradero, como indica Régnier a través de una bella metáfora:

Les poètes récents ont considéré autrement les Mythes et les Légendes. Ils en cherchent la signification permanente et le sens idéal; où les uns virent des contes et des fables, les autres virent des symboles. Un Mythe est sur la grève du temps comme une de ces coquilles où l'on entend le bruit de la mer humaine. Un Mythe est la conque sonore d'une idée (1901b: 336).

${ }^{6}$ Las fluctuaciones entre símbolo y alegoría van a extenderse también al uso del mito que llevarán a cabo los autores fin de siglo. Brunel habla de uso simbólico o uso alegórico del mito. Hay uso alegórico cuando se busca dar una explicación, un sentido dirigido o preciso al uso del mito. De esta manera, perdemos el rasgo esencial del símbolo -su oscuridad-y el sentido último de la práctica simbolista: evocar, sugerir y no describir. Pero: "À cette fausse interprétation symbolique du mythe, qui mérite donc plutôt l'épithète d' "allégorique", nous opposerons l'interprétation multiple à laquelle [...] devrait être réservé le terme de "symbolique". En effet, que le mythe soit considéré comme porteur de plusieurs significations possibles, qu'il renvoie à l'inconnu, au mystère qu'il recouvre, -et le symbole retrouve ses droits» (Brunel 1974: 19-20).

${ }^{7}$ Este «double sens» es el signo característico de la literatura simbolista según este autor: «Ce fut une forme littéraire caractérisée par la fréquence d'œuvres à double sens, c'est-à-dire mythiques et allégoriques. D’une façon plus générale, ce fut une période où, par réaction contre un temps antérieur soucieux d'exactitude et de réalisme, l'art se rejeta vers les sujets de rêve et de légende, et s'attacha à donner à ses œuvres une signification plus lointaine en s'inspirant d'idées philosophiques et religieuses" (Mazel 1968: 337). 


\section{EL MITO Y EL SIMBOLISMO}

El mito «raconte une histoire sacrée; il relate un événement qui a eu lieu dans le temps primordial, le temps fabuleux des "commencements" [...], c'est donc toujours le récit d'une "création": on rapporte comment quelque chose a été produit, a commencé à être» (Eliade 1963: 16 y 17) ${ }^{8}$.

Como apunta Gilbert Durand, el mito trasciende la historia (1993: 32 y 33 ). En cada época de la historia, el ser humano se planteará una serie de cuestiones y buscará las repuestas a estas cuestiones en determinados mitos que adoptarán, por consiguiente, una significación particular ${ }^{9}$. En este sentido, el hombre de la época fin de siglo, inmerso en una sociedad en plena transformación, necesitaba los mitos:

Si l'univers des légendes allait, dans la littérature de l'époque, jouir d'un tel prestige, c'est parce qu'il répondait, à plusieurs titres, à certains des désirs les plus profonds de l'âme fin-de-siècle. Tout d'abord les récits légendaires, parce qu'ils sont toujours situés dans un univers lointain ou reculé dans le temps, à la fois irréel et indécis, satisfaisaient bien à ce désir de dépaysement et d'évasion qu'éprouvait si intensément la conscience collective contemporaine. La nature même des mythes et des récits légendaires, leur caractère souvent accusé d'invraisemblance et de merveilleux, renforçait encore cette dimension imaginaire de la vie quotidienne (Pierrot 2007: 239).

Los autores fin de siglo van a expresan su penchant por el mito en tanto que símbolo, como ya hemos visto en las apreciaciones de Henri de Régnier ${ }^{10}$. Así Emile Verhaeren declarará:

${ }^{8}$ Hemos elegido esta definición entre las muchas que nos ofrecen los estudios sobre el mito porque estamos de acuerdo con Pierre Brunel (1992) cuando afirma que esta es la menos imperfecta y la más completa de las definiciones. Para una visión más completa sobre el mito, vid. Rougemont (1972), Durand (1993), Jolles (1972), Lévy-Strauss (1958), Jung, (1992) y Barthes (1957).

9 "La dimensión atemporal y "ejemplar" del drama o del relato mítico le hace repetible y adaptable a nuevos contextos y situaciones. Escritores de todos los tiempos y de todos los rincones del mundo reformularán con voz propia la intriga en la que se inscribe la acción de los personajes, la orientarán en función de su sensibilidad y enfocarán, desde la dimensión simbólica o metafórica del mito, algún aspecto determinado de la problemática social o moral propia de su contexto histórico» (Herrero Cecilia y Morales Peco 2008: 16).

${ }^{10}$ Las alusiones al mito son frecuentes en los escritos de Henri de Régnier. En sus escritos íntimos encontramos esta otra afirmación: «Il faudrait appuyer certains poèmes sur une sorte de sous-mythologie, qui serait comme la superstition du paganisme et évoquer ces belles choses que sont les dieux ruraux et urbains, les dorures du Faune et du Satyre, les Egéries nymphéennes, tout ce qui sourit aux carrefours ou est dans la profondeur mystérieuse des lueurs» (Régnier 2002: 197). La pregnancia mítica de la obra literaria de Henri de Régnier es asimismo significativa. Además de la importancia de los mitos de Narciso, de Psique, de Orfeo y de Pigmalión, como veremos más adelante, toda la producción de Régnier está marcada por su obsesión por Pan, por los centauros y las ninfas. Debemos destacar también las evocaciones a Hermes en los relatos de Le trèfle noir (Hertulie ou les messages, "D'Hermotine à Hermas", "De Hermas à Hermotine», Histoire d'Hermagore, Hermocrate ou le récit qu'on m'a fait de ses funerailles), la reescritura del viaje de Ulises en Aventure marine et 
L'expression violente du coeur donnée par le Romantisme, l'expression raffinée, discrète, rare de ce même coeur, voilà le rêve, doit être produite à son tour. Et ce seront les sphinx, les anciens rois et les reines fabuleuses et les légendes et les épopées qui nous serviront à nous faire comprendre. Ce seront eux parce qu'ils s'imposent avec le despotisme du souvenir, avec le grandissement séculaire et que nous nous voyons mieux à travers la transparence de leur mythe (Verhaeren 1886, citado por Elgart 2014: 94-95).

El mito, como el símbolo, permite alcanzar la idea, lo que se esconde bajo las apariencias; paralelamente, por lo tanto, posibilita llegar al conocimiento de uno mismo: "Au-delà des millénaires, le mythe offre une image symbolique des mouvements de l'âme. [...] Par le biais du mythe, il ne s'élève plus vers une trascendance divine, mais descend dans les abîmes de son moi -descente salutaire, puisqu'elle conduit à la connaissance de soi»(Elgart 2014: 95).

Esta unión de símbolo y mito explica la coloración mítica que impregna la obra de la mayor parte de los autores de este movimiento ${ }^{11}$. Especialistas como Pierre Brunel (1974) o Bertrand Vibert (2010) ${ }^{12}$ explicitan la importancia de las figuras mitológicas en el Simbolismo. En esta misma línea, otros autores como Pierre Albouy $^{13}$, Natalie Prince ${ }^{14}$, Jean Pierrot ${ }^{15}$, Jean de Palacio ${ }^{16}$ analizan la impronta del mito en la literatura de la Decadencia. A este respecto, creemos que merece la pena destacar que en el uso del mito, Decadencia y Simbolismo, a pesar de ser, desde nuestro punto de vista, movimientos diferentes, presentan muchos puntos en

amoureuse y la alusión a las figuras de Eros y Thanatos en La Mort de Monsieur de Nouâtre et Madame de Ferlinde, ambos de su compilación Monsieur d'Amercoeur. Vid. Imbert (2009).

${ }^{11}$ Así la Hérodiade o L'Après-Midi d'un Faune de Stéphane Mallarmé, las ninfas de Pierre Louÿs, la figura de Sapho en Francis Viélé-Griffin, el mito de Léda en Jean Lorrain, la figura de la mujer fatal en Les diaboliques de Barbey d'Aurevilly... La lista podría ser inagotable (vid. Brunel 1974).

${ }^{12}$ En el capítulo «Exhibition du matériau symbolique» (2010: 170-230), Vibert abunda en la profusión del material mitológico en los autores de la época fin de siglo. Nos refiere el gusto por ciertas figuras como pavos reales, cisnes, faunos..., por los personajes de Orfeo y Narciso, pero también Don Juan o la mujer fatal.

${ }_{13}$ El autor reserva el epígrafe 3, titulado «Symbolistes et Décadents», del capítulo 2 de la 1. ${ }^{a}$ parte de su obra al uso y la simbología de la mitología en esta época. Además, tanto en la segunda parte, dedicada a los mitos de mayor resonancia en la literatura francesa, como en la tercera, consagrada a los autores que presentan un especial tratamiento del mito, se incluyen capítulos cuyo centro de interés es la época fin de siglo (vid. Albouy 1969: 103-120, 173-201 y 270-287).

${ }^{14}$ La antología dirigida por Nathalie Prince (2008) dedica la cuarta parte a los mitos relevantes en la literatura fantástica fin de siglo: Narciso, Pigmalión y Don Juan.

${ }^{15}$ En la segunda parte de su estudio, titulada Les formes de l'imaginaire décadent, Jean Pierrot incluye un capítulo titulado «L'univers des légendes»; en dicho capítulo, el autor, a pesar de la confusión terminológica entre mito y leyenda, hace hincapié en la importancia del mito en la literatura fin de siglo (2007: 240). Dedica también una atención especial a cuatro temas mitológicos concretos: Orfeo, Edipo, la Esfinge y Narciso (2007: 237-255).

${ }^{16}$ Jean de Palacio ha consagrado una trilogía a la literatura decadente $(1990,1993$ y 2000). Dos de las obras que conforman esta trilogía se centran en dos mitos muy queridos en la época fin de siglo: Pierrot y Psique. 
común, fruto de las características propias de la época fin de siglo (vid. Michaud 1947, Dedeyan 1968 y Décaudin y Leuwers 1996).

Por nuestra parte, vamos a detenernos en cuatro de los mitos de predilección del Simbolismo: Narciso, Psique, Orfeo y Pigmalión.

\subsection{NARCiso, LA ILUSTRACIÓN DEL POETA SIMBOLISTA ${ }^{17}$}

La versión más conocida del mito de Narciso aparece en el Canto III de las Metamorfosis de Ovidio y narra la muerte del joven Narciso al contemplar su reflejo en el agua. Las diversas reelaboraciones de las que ha sido objeto responden a las necesidades concretas de cada época, condición indispensable según Albouy para la pervivencia del mito (vid. Volpilhac-Auger 2000; Zaalene 2000; Miguet-Ollagnier 2000; Milner 2000; Foucart 2000; Marchetti 2000; Frølich 2000). En todas ellas, no obstante, el eje central sobre el que se cimenta el mito es la dicotomía yo/otro (tú).

Así, el amor excesivo de uno mismo y la renuncia al amor de los otros se concibe como algo negativo ya desde la Antigüedad clásica. La negación del otro origina desórdenes de identidad y de personalidad. Los psicoanalistas han subrayado los riesgos que conlleva un narcisismo exagerado, los conflictos que acarrea el anclaje en el narcisismo primario ${ }^{18}$.

La relevancia de este mito en el Simbolismo se explica por su relación con la temática de la identidad y del autoconocimiento, aspectos clave de la literatura fin de siglo (vid. Albouy 1969: 173-187). La prueba del interés y fascinación que ejercía el mito de Narciso entre los autores de esta época literaria reside, por ejemplo, en la profusión de obras publicadas con dicho tema, más o menos conocidas, pero todas con la impronta personal del escritor que la $\mathrm{crea}^{19}$. En Henri de Régnier, los versos iniciales de "L'allusion à Narcisse», de su poemario Les jeux rustiques et divins (1897), nos introducen en el mito: «Un enfant vint mourir, les lèvres sur tes eaux, / Fontaine! de s'y voir au visage trop beau / Du transparent portrait auquel il fut crédule...». Los últimos versos muestran la posición de los simbolistas, el poeta adulto es capaz de ver más allá de su reflejo, más allá de la forma material:

17 Vid. el ensayo de Manuel Segade (2008), para comprender la trascendencia de esta figura en la vida artística y literaria de la época fin de siglo.

${ }_{18}$ Remitimos a este respecto a las teorías de Sigmund Freud desarrolladas en «Introducción al narcisismo» (1979, 14: 65-98) y "La psicología de las masas y análisis del Yo» (1979, 18: 63-136) y Jacques Lacan en «Le stade du miroir comme formateur de la fonction du Je» (1949, 449-455).

19 Así, por ejemplo, Les cahiers d'André Walter (1891), Le traité du Narcisse (1891) y Voyage d'Urien (1893), de André Gide; Narcisse parle (1891), Fragments du Narcisse (1919-1922) y Cantate du Narcisse (1939), de Paul Valéry; «L'image» en Le miroir des heures (1892), de Bernard Lazare; Discours sur la mort de Narcisse ou l'impérieuse métamorphose (1895), de Saint-Georges Bouhélier; Le Miroir, de Jean Richepin (1899); Soeur de Narcisse (1907), de Jean Royère; Narkiss, de Jen Lorrain (1908). La lista es demasiado extensa para consignar todas las obras. 
Et, dans la source claire où j'avais voulu boire,

Je m'entrevis comme quelqu'un qui s'apparaît.

Était-ce qu'à cette heure, en toi-même, mourait

D'avoir voulu poser ses lèvres sur les siennes

L'adolescent aimé des miroirs, ô Fontaine? (1908: 16).

«L'Escalier de Narcisse», una de las partes que configuran el relato Hertulie ou les messages, perteneciente a la colección Le trèfle Noir (1895), es un ejemplo más. En este texto se describe con sumo detalle una enorme fuente conformada por diversos estanques que se suceden y parecen multiplicarse hasta el infinito. La escalera que nos conduce hasta dicha fuente lleva por nombre Escalier de Narcisse. En ella, Hermas y Hermotine se sientan a reposar y conversar mientras escuchan el «eco» del agua de la fuente. Este relato cumple la máxima de Mallarmé y nos parece un ejemplo paradigmático de la visión simbólica de los mitos por parte del Simbolismo:

Hermas et Hermotine s'y reposèrent souvent, d'ordinaire sur cette dernière marche, au bas de l'Escalier de Narcisse. [...] Hermotine aimait s'arrêter auprès de la petite source. Hermas préférait s'accouder nonchalamment aux sphinx de marbre ou caresser l'écaille cambrée des dauphins de porphyre. L'écho ne répéta jamais rien en le faussant de ce que les deux amis se dirent à demi-voix. Leur concorde appariait leurs différences. Un jour suivirent une des allées d'eau jusques à cette fontaine où souriait une statue singulière. Hermas y vit un songe; Hermotine y supposa un symbole; ils revinrent sans parler, car le crépuscule déclinait déjà et les eaux, s'étant tues, invitaient au silence (1926: 139-140).

Junto a los textos de Henri de Régnier, otro ejemplo destacado es el Traité $d u$ Narcisse, Théorie du symbole, de André Gide $(1948)^{20}$. Gide, a pesar de alejarse pronto de los círculos simbolistas, forja una teoría del símbolo a partir del mito de Narciso, sumándose de esta manera a los autores que manifestaban la estrecha relación entre mito y símbolo.

Gide nos presenta a un Narciso ocioso, andrógino, en el paraíso. Sin embargo, osa romper una rama del árbol Ygdrasil y la armonía se rompe y aparece el «otro», la mujer. A partir de ese momento, nada es real. Todo es reflejo, imagen, ilusión. La auténtica realidad está bajo el envoltorio material de cada objeto o ser de este mundo. Todos los esfuerzos deben concentrarse en desvelar la esencia verdadera y auténtica que se esconde bajo el envoltorio exterior y que se oculta a nuestros ojos a primera vista (vid. Gide 1948: 19).

Las reflexiones de Gide nos recuerdan evidentemente el discurso de Platón, pero más aún el de los neoplatónicos. Platón establece una dualidad entre las ideas y las sombras, Plotino y sus discípulos establecen las relaciones de este mundo mate-

${ }^{20}$ Este ensayo fue escrito por Gide en 1891 y publicado en el número 22 (enero de 1892) de la revista Entretiens politiques et littéraires. 
rial con el mundo Inteligible a través de una serie de correspondencias -reflejos de reflejos- interminables que van de lo intangible hasta lo más material.

Los fundamentos del Simbolismo se encuentran aquí. Pero ¿̇cómo acceder a la forma secreta?

Les Vérités demeurent derrière les Formes — Symboles. Tout phénomène est le Symbole d'une Vérité. Son seul devoir est qu'il la manifeste. Son seul péché: qu'il se préfère.

Nous vivons pour manifester. Les règles de la morale et de l'esthétique sont les mêmes: toute œuvre qui ne manifeste pas est inutile et par cela même, mauvaise. Tout homme qui ne manifeste pas est inutile et mauvais. (Gide 1948: 21, nota 1).

La respuesta del Simbolismo es clara: a través del símbolo. El símbolo nos permite despojarnos de lo material y quedarnos con la Verdad. Esta es la tarea y el deber del poeta: comunicar la verdad, la idea, «manifestar». Así, Narciso «symbolise le poète qui, derrière les apparences imparfaites, veut découvrir les archétypes et les essences; et l'eau représente l'œuvre d'art [...]» (Favre 1988: 1074).

El poeta que se extravía y equivoca el camino con la mala utilización del lenguaje y del símbolo corre el riesgo de gustarse a sí mismo y buscar el adorno superficial, como Narciso, que, contemplando su imagen en el agua, se deja atrapar por su belleza exterior. Cae en el pecado de "gustarse», de "preferirse», así no busca en su interior, no se conoce (vid. Gide 1948: 21, nota 1).

Ese es el error de otras estéticas: no persiguen la verdad, sino que buscan gustarse a sí mismas y por ello hacen un uso equivocado del símbolo. El poeta simbolista, por el contrario, «devine à travers chaque chose et une seule lui suffit, symbole, pour révéler son archétype; il sait que l'apparence n'en est que le prétexte, un vêtement qui la dérobe et où s'arrête l'oeil profane, mais qui nous montre qu'Elle est là» (Gide 1948: 24).

Con igual relevancia que el mito de Narciso, aparece la historia de los amores de Psique. El mito de Psique fue inmortalizado por Apuleyo en El asno de oro. La interpretación del mito ha evolucionado con el paso de los siglos. De símbolo de la curiosidad a símbolo del deseo de conocimiento y de la interioridad:

[...] au fur et à mesure que l'on avance vers l'époque décadente, un registre que l'on pourrait qualifier d'intimiste, dans lequel, bien moins que la signification globale et universelle du mythe, est mise en jeu sa signification individuelle, personnelle, attachée aux espaces du moi et aux horizons les plus cachés et les plus obscurs (Sozzi 2000: 377). 


\subsection{PSIQUe Y «LE LOGIS INTÉRIEUR» ${ }^{21}$}

Apuleyo nos presenta un personaje femenino, que sufre las consecuencias de la cólera de Afrodita. Encerrada en una cueva y condenada a la ignorancia sobre el aspecto y la identidad de su amante, cae en la tentación y enciende la lámpara de la desdicha. A lo largo de los siglos, el tema de la mirada escondida y de la curiosidad femenina fueron ejemplificados con este mito:

C'est dans le contexte du désir que le regard se découvre comme interdit, depuis l'Antiquité grecque. Le regard désirant est rendu tabou, comme s'il était déjà en soi un contact et un objet sexuel. Refoulé, le regard revient à sa place pour semer le désordre, et pour faire effraction dans le sacré. Dans les mythes construits autour des dieux gréco-romains, le regard qui fait retour provoque des drames (Schlossman 2000: 365).

Y así se muestra de entrada también en el siglo XIX: «Dans la modernité, Psyché apparaît dans le contexte du regard interdit tel que la lecture l'impose, aprèscoup, au Poète de l'imagination" (Schlossman 2000: 371).

Jean de Palacio (2000) ha estudiado las transformaciones del mito de Psique desde la historia de Apuleyo hasta el primer tercio del siglo xx. De Palacio estructura su estudio en dos partes, tomando como eje vertebrador la figura femenina de Psique. En la primera parte, plantea la cuestión de la importancia de este mito con respecto a las líneas de fuerza de la estética fin de siglo. Así, el autor nos presenta los amores de Psique con Eros, representaciones del alma y del cuerpo respectivamente, y los objetos que se asocian a Psique, como el espejo y la lámpara. En la segunda parte, el autor nos acerca a las «perversiones» operadas en la fin-de-siècle. Psique será representada como una figura depravada, como una esclava, como una víctima... Este estudio de Jean de Palacio demuestra la relevancia del mito de Psique en la época literaria que nos ocupa.

Desde los antecedentes de Théophile Gautier con Melle de Maupin (1835), Fortunio (1837), Avatar (1856), Spirite (1865), entre otras, en las que ya se vislumbra el cambio de tendencia, las reminiscencias de este mito son notables en las obras literarias del periodo fin de siglo 22 .

Queremos detenernos una vez más en Henri de Régnier, quien, además de utilizar de manera recurrente este personaje de la mitología en su obra, por ejemplo en su poema "La Lampe», en La sandale ailée (1906), o en el cuento «Les dîners singuliers", de La canne de jaspe (1897) ${ }^{23}$, adoptará este elemento como símbolo de su poética personal.

${ }^{21}$ Expresión que tomamos prestada de «Le bosquet de Psyché» (Régnier 1901a: 295).

22 Ejemplos de reescritura del mito son, por ejemplo, «L'ami des miroirs», de Le rouet des brumes (1901), de Rodenbach; Catulle Mendès y su Femme-enfant (1891); la Psychée de Pierre Louÿs (1927), etc.

${ }^{23}$ En sus novelas, además, la figura de Psique aparece siempre ligada a la relación amorosa de los personajes, los personajes femeninos serán más o menos explícitamente las encarnacio- 
En su estudio «Le bosquet de Psyché» (1901), que recoge las conferencias pronunciadas en el Cercle Artistique et Littéraire de Bruxelles en 1894, Henri de Régnier convierte a Psique en el símbolo que ilumina y organiza su concepción estética: «Le point de départ original de Régnier se trouve dans la conjonction entre le mythique personnage et le culte de l'Art. Psyché dort en nous et ne se réveille que si nous savons lui offrir les fleurs de la contemplation et de la création...» (Sozzi 2000: 383).

El arte para Régnier es fruto de la introspección, de la búsqueda interior. A través de la meditación, de la contemplación, del rêve, accedemos a Psique, al alma, condición sine qua non para despojarnos de lo fútil y quedarnos con lo esencial:

Pour tous cette chambre de Psyché peut être un lieu charmant, secret et délicieux. Elle figure ce qu'il y a en chacun de fin, de délicat et d'un peu supérieur. Elle est le dégagement aérien de notre terrestréité; l'âme y est à l'aise de pouvoir délasser la contrainte qu'impose la vie à ce qu'il y a d'ailes dans sa démarche. C'est là qu'il faut abriter les instants qu'on dérobe à la vie; on y reprend contact avec je ne sais quel instinct d'idéal qui est en nous. On soupèse la cendre qu'ont laissée dans notre main les vaines amours et les pauvres désirs, cendre amère, mais légère. Psyché la frôle de son aile et elle se dissipe (Régnier 1901a: 294-295).

La lámpara de Psique, símbolo negativo que desencadena el drama en el mito clásico, se torna en símbolo iluminador que nos guía en nuestro camino: «Paradoxalement c'est justement cette lampe de Psyché qui, dans le mythe, marque le debut de ses mésaventures, c'est elle qui, pour Régnier, [...], devient la lumière idéale qui nous préserve de toute chute dans le mediocre et dans le vain...» (Sozzi 2000: 385).

Todo hombre se inclina hacia la belleza y la poesía, debemos buscarla en nuestro interior; con ayuda de la lámpara llegaremos hasta Psique:

Il y a en tout homme un désir de poésie et de beauté. Si cet instinct ne peut pas se réaliser, il peut au moins se reconnaitre; infirme, il est clairvoyant. Prenons donc à la main la lampe idéale qui brûle faiblement au fond de notre nuit, et descendons les marches intérieures avec notre ombre devant nous. Voici le lieu où celle qui dort va s'éveiller à l'incantation des poètes et la voici qui se dresse, hors des langes de notre oubli, devant nous et en nous-même, résurrectrice, la statue chaste de nos rêves et la figure de nos songes (Régnier 1901a: 299-300).

En este contexto, no es de extrañar que Orfeo se erija en el símbolo por excelencia del poeta. Con Virgilio: "Orphée apparaît comme le poète civilisateur et fondateur de la religion, le mage qui révèle les secret divins» (Albouy 1969: 188).

nes de Psique, así como los personajes masculinos serán las representaciones de Eros. La figura de la madre castradora tan importante en la temática de Régnier corresponde a la diosa Afrodita. Vid. a este respecto la tesis de Essawy (2000), quien analiza la importancia de este mito en La Pécheresse, L'Escapade, La Flamblée y Romaine Mirmault. 


\subsection{Orfeo: el poeta de L'IDÉaL}

Virgilio canta al final del libro iv de las Geórgicas la historia de Orfeo y Eurídice. Orfeo, desolado por la pérdida de su esposa, desciende al inframundo para recuperarla, con la condición de no echar la vista atrás. Cuando ya casi ha cumplido la misión, vuelve la cabeza y su esposa se desvanece definitivamente. Orfeo muere poco después despedazado por las Bacantes.

Como dice Albouy, «c'est de la philosophie idéaliste, de la poésie conçue comme symbole des vérités cachées qu'Orphée devait attendre sa plus grande faveur» (1969: 189 $)^{24}$. Lo que atrae fundamentalmente a los escritores fin de siglo del mito de Orfeo «c'est moins le thème de la descente aux Enfers et de la résurrection d'Euridyce, [...] que celui du poète-magicien tout-puissant sur les éléments, les rochers, les animaux sauvages et les humains grâce au prestige de son chant» (Pierrot 2007: 249).

Nos vamos a detener en un relato de Henri de Régnier, Manuscrit trouvé dans une armoire, incluido en la colección Contes à soi-même (1894). Las fuentes de este relato son, por una parte, el cuento de E.A. Poe Manuscrito encontrado en una botella y, por otra, el cuadro de Gustave Moreau Jeune Fille thrace portant la tête d'Orphée (1865) (vid. Vibert 2011: 459-463).

Manuscrit trouvé dans une armoire presenta una estructura tripartita. El relato del narrador, que transmite su errance; el encuentro con Eurydice -y su amor por ella-; y la narración de esta, que no es, ni más ni menos, que la transposición en palabras de las imágenes del cuadro de Moreau. La identificación del narrador con la figura de Orfeo se evidencia en estas líneas: «’appuyai ma tête par mélancolie et par tendresse sur les genoux d'Eurydice. Elle la soutenait de ses belles mains: elle semblait la soupeser» (Régnier 1926: 254). La delicadeza del relato y la melancolía que transmite hacen de él una de las joyas de la prosa simbolista régnieriana.

No es esta la única obra en la que podemos observar la plasmación del mito de Orfeo. Las figuras de Orfeo y de Eurídice se perciben en gran parte de sus novelas. El caso más relevante es quizás La Pécheresse: M. de la Péjaudie y Mme de Séguiran son vistos como los amantes trágicos Orfeo y Eurídice. Impresión acrecentada por el hecho de que $M$. de la Péjaudie es un excelente músico que encandila a Mme. de Séguiran con los sonidos que extrae de su flauta (vid. Essawy 2000: 378-381).

Psique, Narciso y Orfeo son un ejemplo fundamental a la hora de entender la concepción y la utilización del mito en la literatura finisecular. Ejemplos de la preocupación por la interioridad y el conocimiento, la asunción de estos mitos por parte de los autores responde a sus principios literarios. Tanto Gide como Régnier se sirven de estas figuras para trasmitirnos sus ideales estéticos. Junto a estos mitos que revelan la obsesión por la identidad, encontramos otros que desnudan la alteridad.

${ }^{24} \mathrm{Y}$ así, en la época que nos ocupa, encontramos numerosos testimonios escritos de la preferencia por este mito, como, por ejemplo, el libro de Édouard Schuré Les Grands Initiés (1889); el relato La Lyre, perteneciente a la colección Le miroir des légendes (1892), de Bernard Lazare; el poema de Paul Valéry «Orphée» (1891), recogido posteriormente en el poemario Album de vers anciens (1920); la historia Dans un monde sonore, de Victor Ségalen (1907). 


\subsection{Pigmalión: El ARTista-Creador}

El mito de Pigmalión aparece en las Metamorfosis de Ovidio, en el Libro X, dentro del Canto de Orfeo. Tiene una extensión muy limitada, apenas 50 versos. Su conexión con el mito de Orfeo se atestigua ya desde los orígenes.

Este mito ocupa un lugar destacado en la literatura francesa del siglo XIX, no como una simple copia sino con signos evidentes de renovación. Así, el mito evoluciona desde el modelado de la estatua hasta la transformación de la estatua en mujer artificial. Entre un paso y otro, el mito aparece con ropajes diferentes. El Romanticismo será, una vez más, el momento en el que se opere la revolución: «Le Romantisme [...] se plaît à insuffler tout particulièrement un sens neuf au mythe de Pygmalion, dans lequel il lit le condensé de ses valeurs les plus chères: rupture dans l'ordre établi, bouleversement des règnes terrestre et divin, autofondation de l'artiste» (Geisler-Szmulewicz 1999: 379).

En efecto, algunas de las obras literarias de mayor repercusión que presentan una reescritura del mito de Pigmalión son fruto del Romanticismo: El hombre de arena, de E.T.A. Hoffmann (1817); Frankenstein, de Marie Shelley (1818); La Vénus d'Ille, de Prosper Mérimée (1837); o El retrato oval, de E.A. Poe (1845) (vid. Rueda 1998).

Nathalie Prince, centrándose en las obras fin de siglo, señala también la importancia de la animación de la estatua. Pero, además, la autora incide en otro aspecto esencial, la relación del mito de Pigmalión con la manifestación de la alteridad y la plasmación de esta en el ser artificial:

Le "pygmalionisme» contient à l'évidence un certain nombre d'éléments bien connus du fantastique -l'animation d'un objet ou encore l'histoire d'amour improbable entre un vivant et un objet- et de valeurs decadentes: il n'y a pas de pygmalionisme sans un dualisme idéal/réel, idéal/nature, artífice/nature et dépassement de la nature par l'art. Pygmalion, c'est l'affirmation que la nature et la réalité sont insuffisantes en soi, qu'elles appellent et impliquent un dernier geste poétique et artistique pour être parfaites (2008: 799).

Y estos dos aspectos serán la herencia que reciban los autores del Parnaso, decadentes, simbolistas; en definitiva, aquellos que conciban el Arte y lo Bello como la vía que el artista debe seguir indefectiblemente. Así, «le mythe de Pygmalion représente de manière exemplaire la sacralisation de l'Art et l'amour exclusif du Beau» (Geisler-Szmulewicz 1999: 379).

L'Ève future, de Villiers de L'Isle Adam (1886), representa el punto culminante de esta transformación, pero no es el único ejemplo. Así, otros testimonios son La Statue, de Georges Godde (1886); La Statue, de Gustave Geffroy (1894); Les fugitives y La Robe, pertenecientes a la colección Histoires Magiques, de Rémy de Gourmont (1894); Le marbre, de Michel Corday (1896); La femme de marbre, de Henri de Régnier (1901); La statue ensoleillée (1909) y La Gloire du Comacchio, de Maurice Renard (1913) (vid. Prince 2008: 795-963). 
La renovación se hace a partir de una serie de elementos estable ${ }^{25}$ que nos tienen que permitir reconocer el mito a pesar de sus posibles variantes. Max Milner dice a este respecto: «Le mythe de Pygmalion, [...] est sous-jacent à tous les romans qui ont pour thème la folie du peintre ou du sculpteur, avec, cependant, des variations notables» (1989: 7).

Anne Geisler-Szmulewicz nos habla de una característica fundamental de la escritura del siglo xix en lo que respecta a la utilización de los mitos, lo que ella llama "coalescence des mythes», que define como «la rencontre entre deux mythes différents qui produit le renouvellement de la signification de chacun d'eux. [...] Il [ce phénomène] joue un rôle capital dans les réécritures du mythe de Pygmalion au XIX ${ }^{e}$ siècle» (1999: 16 y 17). Así, «le mythe de Pygmalion sera fédéré, au XIX ${ }^{e}$ siècle, aussi bien avec les mythes de Prométhée, de Méduse, de Daphné, de Niobé, qu'avec ceux de l'Androgyne et de Narcisse, de l'automate et du magicien» (1999: 22), todos ellos mitos de alta simbología en la época fin de siglo. La autora analiza en profundidad este fenómeno de la "coalescence» en los binomios Pigmalión-Prometeo, Pigmalión-Andrógino y en la triada Pigmalión-Andrógino-Narciso (vid. 1999: 85,136 y 165).

Este concepto de coalescence puede aplicarse a nuestro parecer al relato $L a$ femme de marbre, de Henri de Régnier. El artista de La femme de marbre encarna de alguna manera a Prometeo, en el sentido de que se hace creador, modelador. Da forma e insufla vida a su escultura. Al mismo tiempo, queda al descubierto el componente cristiano; el artista, como nuevo Jesucristo, escenifica un proceso iniciático que le lleva, por la vía de la purificación de su cuerpo y de su alma -alimentándose exclusivamente de pan y vino: «Un morceau de pain mangé debout, un verre de vin bu à la hâte, formaient toute ma nourriture» (Régnier 1923: 12)-, a la potestad de crear o de quitar vida: "Il ne me restait plus qu’à choisir ce que je voulais éterniser. J'avais résolu que ce fût un corps de femme, en souvenir de celle dont le baiser m'avait ouvert les yeux...» (1923: 18).

El mito de Pigmalión se manifiesta de manera mitigada y con variantes a través de dos elementos: por una parte, el amor del autor y, sobre todo, de los amantes hacia la modelo «auténtica» $y$, por otra, la animación de la estatua que quita la vida a la modelo. De esta manera, la estatua se convierte en figura de mujer fatal, fascinadora y mortal y nos remite, por tanto, al mito de Salomé. Los Corcorone, amantes obsesionados, se matan uno al otro bajo la mirada de la femme de marbre: «On les trouva tous les deux morts, un matin, aux pieds de la statue de Giulietta. L'un avait au cœur la pointe d'une dague à pommeau de perle; l'autre, dans la gorge, la pointe d'une dague à pommeau de rubis; et leur double sang ne faisait sur la dalle qu'une seule flaque rouge» (1923: 48-49).

${ }_{25}$ "Ce qui doit guider la reconnaissance des variantes d'un mythe, ce sont les éléments stables qui se transmettent d'une œuvre à une autre, sans que l'écrivain qui s'en empare ait même besoin de revenir à la version primitive». (Geisler-Szmulewicz 1999: 15). Para la autora, los elementos invariables del mito de Pigmalión son: «l'amour du créateur pour sa création, l'animation de l'œuvre et le caractère transcendant du miracle» (1999: 16). 
La femme de marbre acaba con la destrucción de la estatua a manos de su creador, que se erige así en salvador. Es un combate a muerte en el que, al final, los papeles se invierten y Salomé acaba perdiendo la cabeza, que rueda a los pies del artista:

Je la regardai une dernière fois, puis je levai le bras et je frappai lourdement.

À chaque coup, le marbre volait en éclats et se marquait d'écorchures blanches. La noble matière criait ou gémissait à l'insulte, selon que le fer la heurtait ou l'éraflait. Elle repoussait mon effort de toute sa vivante solidité. C'était moins une destruction qu'un combat. Un fragment aigu me jaillit au front; je saignai. Une sorte de fureur m’avait saisi qui se changea en une rage forcenée. Parfois j'étais honteux de battre une femme. Parfois il me semblait me défendre contre une ennemie. [...] Les bras se brisèrent; je m'attaquai aux genoux; une jambe casa, puis l'autre, et la statue oscilla; elle tomba en avant sur la dalle. Ce n'était plus qu'un bloc indistinct. La tête épargnée se détacha et roula jusqu'à mes pieds (1923: 49-50).

\section{CONCLUSIÓN}

En este estudio, hemos analizado el concepto de símbolo como elemento estructurador de la estética simbolista. Hemos mostrado cómo el uso del símbolo, heredado del Romanticismo alemán, es el eje sobre el que pivotan las concepciones idealistas del Simbolismo. La estética idealista es asimismo responsable de la importancia del mito en el periodo finisecular. Tanto el Simbolismo como la Decadencia harán un uso simbólico del mito que se erige así en motor de las producciones literarias. Narciso, Psique, Orfeo y Pigmalión plasman las grandes preocupaciones del periodo finisecular en torno a la concepción de un yo problematizado, que se debate entre la soledad narcisista y la apertura al otro. Para ilustrar estas ideas, hemos fijado nuestra atención en algunos textos literarios de este periodo, fundamentalmente de Henri de Régnier. Este autor, que milita en las filas simbolistas, explora incesantemente, tanto en su obra poética como prosística, las fronteras de la identidad y el conocimiento de uno mismo. En este sentido, su producción, pensamos, es un claro ejemplo del uso simbólico del mito. Las constantes alusiones a Narciso, Psique, a Orfeo y a Pigmalión en su obra nos permiten afirmarlo. De hecho, Psique, como hemos mostrado en este estudio, representa el símbolo que organiza la estética literaria de este autor, hoy injustamente olvidado. 


\section{BIBLIOGRAFÍA}

Albouy, Pierre (1969): Mythes et Mythologie dans la littérature Française, París: Armand Colin.

BACKÈs, Jean-Louis (1980): «La pratique du symbole», Littérature, 40, 3-17. URL: http://www.persee.fr/doc/litt_0047-4800_1980_num_40_4_2144; 24/02/ 2017.

Barthes, Roland (1957): Mythologies, París, Seuil.

Besnier, Patrick (2015): Henri de Régnier. De Mallarmé à l'Art déco, París: Fayard.

Brunel, Pierre (1992): Mythocritique. Théorie et parcours, París, PUF.

Brunel, Pierre (1974): «L' “au-delà” et l' “en-deça”: place et fonction des mythes dans la littérature symboliste», Neohelicon: Acta Comparationis Literarum, 2 (3-4): 11-29.

Décaudin, Michel y Daniel leuwers (1996): Histoire de la littérature française. De Zola à Apollinaire, París: Garnier-Flammarion.

Dedeyan, Charles (1968): Le nouveau mal du siècle. De Baudelaire à nos jours, París: Société d'Édition d'Enseignement Supérieur.

Durand, Gilbert (1993): De la mitocritica al mitoanálisis. Figuras míticas y aspectos de la obra, Barcelona: Anthropos, México: Universidad Autónoma Metropolitana-Iztapalapa.

Elgart, Jutta (2014): Symbolisme et figures mythiques et légendaires: une vision européenne (Stéphane Mallarmé, William Butter Yeats et Stefan George), Thèse de Doctorat, Université Toulouse le Mirail-Toulouse II, <NNT:2014TOU20057>. <tel-01256620>. URL: https://tel.archives-ouvertes.fr/tel-01256620; 20/02/2017.

Eliade, Mircea (1963): Aspect du mythe, París: Gallimard.

Essawy, Géhane (2000): Henri de Régnier romancier. Du psychologique au narratif: à la recherche d'un moi et d'un amour perdus, Thèse de Doctorat, Université Paris IV.

Favre, Yves-Alain (1988): «Narcisse», en Pierre Brunel (dir.), Dictionnaire des mythes littéraires, París: Éd. Du Rocher.

Foucart, Claude (2000): «Le Narcisse de Gide (1893) ou le passage du mythe au symbole», en Pascale Auraix-Jonchière (ed.), Isis, Narcisse y Psyché, Entre Lumières et Romantisme, ClermontFerrand: Presses Universitaires Blaise Pascal, 241-252.

Freud, Sigmund (1979): «Introducción al narcisismo», en Obras Completas, 14 (1914-1916), Buenos Aires: Amorrortu editores, 65-98.

Freud, Sigmund (1979): «La psicología de las masas y análisis del Yo», en Obras Completas, 18 (19201922), Buenos Aires: Amorrortu editores, 63-136.

FrøLICH, Juliette (2000): «Face à son Coeur, Narcisse fin de siècle», en Pascale Auraix-Jonchière (ed.), Isis, Narcisse y Psyché, Entre Lumières et Romantisme, Clermont-Ferrand: Presses Universitaires Blaise Pascal, 287-298.

Geisler-Szmulewicz, Anne (1999): Le mythe de Pygmalion au XIX siècle. Pour une approche de la coalescence des mythes, París: Honoré Champion.

Gide, André (1948): Le traité du Narcisse, Théorie du Symbole en Le retour de l'enfent prodigue, París: Gallimard.

Gide, André y Henri de RÉGnier (1997): Correspondance (1891-1911), D.J. Niederauer et H. Franklyn (eds.), Lyon: Presses Universitaires de Lyon. 
Hernández-Pacheco, Javier (1995): La conciencia romántica, Madrid: Tecnos.

Herrero Cecilia, Juan y Montserrat Morales Peco (eds.) (2008): Reescrituras de los mitos en la literatura, Cuenca: Ediciones de la Universidad de Castilla-La Mancha.

Huret, Jules (1891): Enquête sur l'évolution littéraire, París: Bibliothèque Charpentier.

Illouz, Jean-Nicolas (2004): Le symbolisme, París: Le Livre de Poche.

Imbert, Christophe (2009): «La grande mélancolie des Dieux titaniques: une approche de la "métaphysique terrienne" des poètes de la Romania», en J.-P. Aygon, C. Bonnet y C. Noacco (eds.), La mythologie de l'Antiquité à la Modernité, Rennes: Presses Universitaires de Rennes.

Jolles, André (1972): Formes Simples, París: Seuil.

JunG, C.G. (1992): L’homme et ses symboles, París: Robert Laffont.

Juszezak, Joseph (1985): Les sources du Symbolisme, París: SEDES.

LaCAN, Jacques (1949): «Le stade du miroir comme formateur de la fonction du Je», Revue française de psychanalyse 4, 13, 449-455.

Leoutre, Gilbert y Pierre salomon (1970): Baudelaire et le Symbolisme, París: Masson et Cie.

LÉvy-Strauss, Claude (1958): «La structure des mythes», en Anthropologie structurale, París: Plon.

Maeterlinck, Maurice (1979): Préface, en Théatre, París-Ginebra: Honoré Champion, 1. ${ }^{a}$ edición 1901-1902, X-XI.

Marchetti, Adriano (2000): «Le Narcisse de Gide et le mythe de l'androgyne», en Pascale AuraixJonchière (ed.), Isis, Narcisse y Psyché, Entre Lumières et Romantisme, Clermont-Ferrand: Presses Universitaires Blaise Pascal, 253-262.

Mercier, Alain (1969): Les sources ésotériques et occultes de la poésie symboliste (1870-1914), I, Le symbolisme français, París: Nizet.

Michaud, Guy (1947): Message poétique du symbolisme, París: Nizet.

Miguet-Ollagnier, Marie (2000): «Le Narcisse ou l'amant de lui-même de Jean-Jacques Rousseau", en Pascale Auraix-Jonchière (ed.), Isis, Narcisse y Psyché, Entre Lumières et Romantisme, Clermont-Ferrand: Presses Universitaires Blaise Pascal, 193-202.

Milner, Max (1989): «Le peintre fou», Romantisme, Folie de l'art, 66: 5-21. URL: http://www.persee.fr/doc/roman_0048-8593_1989_num_19_66_5624; 15/06/2018.

Milner, Max (2000): «Narcisse maléfique: le thème du miroir chez Théophile Gautier», en Pascale Auraix-Jonchière (ed.), Isis, Narcisse y Psyché, Entre Lumières et Romantisme, ClermontFerrand: Presses Universitaires Blaise Pascal, 217-230.

MorÉAS, Jean (18 septembre 1886): «Un manifeste littéraire», Le Figaro, 38. URL: http://gallica.bnf. fr/ark:/12148/bpt6k2723555/f2.item; 14/03/2017.

Palacio, Jean de (1990): Pierrot Fin de siècle, París: Éditions Séguier.

Palacio, Jean de (1993): Les Perversions du merveilleux, París: Éditions Séguier.

Palacio, Jean de (2000): Les Métamorphoses de Psyché. Essai sur la décadence d'un mythe, Biarritz: Éditions Séguier, Atlantica.

Pierrot, Jean (2007): L'Imaginaire décadent (1880-1900), Rouen: Publications des Universités de Rouen et du Havre.

Prince, Nathalie (2008): Petit musée des horreurs. Nouvelles fantastiques, cruelles et macabres, París: Robert Laffont. 
Quiriny, Bernard (2013): Monsieur Spleen. Notes sur Henri de Régnier, París: Seuil.

Regnier, Henri de (1901a): «Le bosquet de Psyché», en Figures et Caractères, París: Mercure de France.

RÉgnier, Henri de (1901b): «Poètes d'aujourd'hui et Poésie de demain», en Figures et Caractères, París: Mercure de France.

RÉGNIer, Henri de (1906): La sandale ailée, París: Mercure de France.

RÉGnier, Henri de (1908): Les jeux rustiques et divins, París: Mercure de France.

Regnier, Henri de (1923): Les Amants singuliers, París: Mercure de France.

RÉGnier, Henri de (1926): La canne de jaspe, París: Mercure de France.

RÉGNier, Henri de (2002): Les cahiers inédits 1887-1936, París: Pygmalion/Gérard Watelet.

Rougemont, Denis de (1972): L'Amour et l'Occident, París: Plon.

Rueda, Ana (1998): Pigmalión y Galatea: Refracciones modernas de un mito, Madrid: Fundamentos.

Saint-Antoine (Henri Mazel) (1968): "Qu'est-ce que le symbolisme?», L'Ermitage, Janvier-juin 1894, 8, Ginebra, Slatkine Reprints, 332-337. URL: https://gallica.bnf.fr/ark:/12148/ bpt6k155629; 13/03/2017.

Schlossman, Beryl (2000): «Le retour du regard: Psyché, le féminin et les voiles de l'allégorie», en Pascale Auraix-Jonchière (ed.), Isis, Narcisse y Psyché, Entre Lumières et Romantisme, Clermont-Ferrand: Presse Universitaires Blaise Pascal, 365-375.

Segade, Manuel (2008): Narciso fin de siglo, Santa Cruz de Tenerife: Melusina.

Sozzi, Lionello (2000): «Amour et Psyché entre romantiques et décadents», en Pascale Auraix-Jonchière (ed.), Isis, Narcisse y Psyché, Entre Lumières et Romantisme, Clermont-Ferrand: Presse Universitaires Blaise Pascal, 377-391.

Varhaeren, Émile (1982): Art Moderne, 12/09/1886, en Robert L. Delevoy, Le Symbolisme, Éditions Skira: Ginebra.

Vibert, Bertrand (2010): Poète, même en prose, París: Presses Universitaires de Vincennes.

Vibert, Bertrand (éd.) (2011): Contes symbolistes, vol. II, Grenoble: ELLUG.

Volpilhac-Auger, Catherine (2000): «Narcisse au miroir de la fable ou les métamorphose d'Ovide», en Pascale Auraix-Jonchière (ed.), Isis, Narcisse y Psyché, Entre Lumières et Romantisme, Clermont-Ferrand: Presses Universitaires Blaise Pascal, 23-34.

ZaAlene, Sabine (2000): «Peindre, c'est embrasser la surface de la source: Narcisse, la Peinture dans les œuvres françaises du XVIII ${ }^{\mathrm{e}}$ siècle», en Pascale Auraix-Jonchière (ed.), Isis, Narcisse y Psyché, Entre Lumières et Romantisme, Clermont-Ferrand: Presses Universitaires Blaise Pascal, 181-192. 
